\section{Uphill or downhill bleeding?}

\section{INTRODUCTION}

An 87-year-old woman presented with a 2-day history of melaena and symptomatic anaemia. Medical history included idiopathic hyperthyroidism, a gastric ulcer and diverticular disease. On arrival, vital signs were stable apart from a tachycardia (107 bpm). Her initial haemoglobin was $48 \mathrm{~g} / \mathrm{L}$ and urea $32.7 \mathrm{mmol} / \mathrm{L}$. A large anterior neck mass was observed on examination.

At endoscopy, this abnormality was identified in the upper oesophagus (figure 1). Minimal gastritis and a normal duodenum were also observed. Subsequently cross-sectional imaging of the chest abdomen and pelvis was undertaken to investigate the neck mass (figure 2).

\section{QUESTION 1}

What is the abnormality in the upper oesophagus and how should it be managed?

\section{QUESTION 2}

What is the significance of the right sided neck mass?

\section{ANSWER}

The patient had developed proximal oesophageal varices (figure 1) due to venous compression by a large goitre (figures 2 and 3 (arrow)). Grade 2 oesophageal varices were seen in the upper third of the oesophagus at the 11 o'clock position (figure 1 (arrow)) with no stigmata of recent bleeding and no red wale sign. The absence of portal hypertensive gastropathy at endoscopy, and the unusual variceal location suggests a cause other than portal hypertension. Additionally, no other features to suggest underlying portal hypertension or chronic liver disease were noted including a normal liver, spleen and absence of ascites on CT imaging (figure 3). The varices were managed without intervention with a strategy of watchful expectancy. Surgery, the definitive treatment of intrathoracic goitre, was declined by the patient.

Isolated proximal oesophageal varices are rare with an incidence of $0.5 \%$ of upper gastrointestinal endoscopies in a recently reported observational study. ${ }^{1}$ Development is often due to extrinsic processes

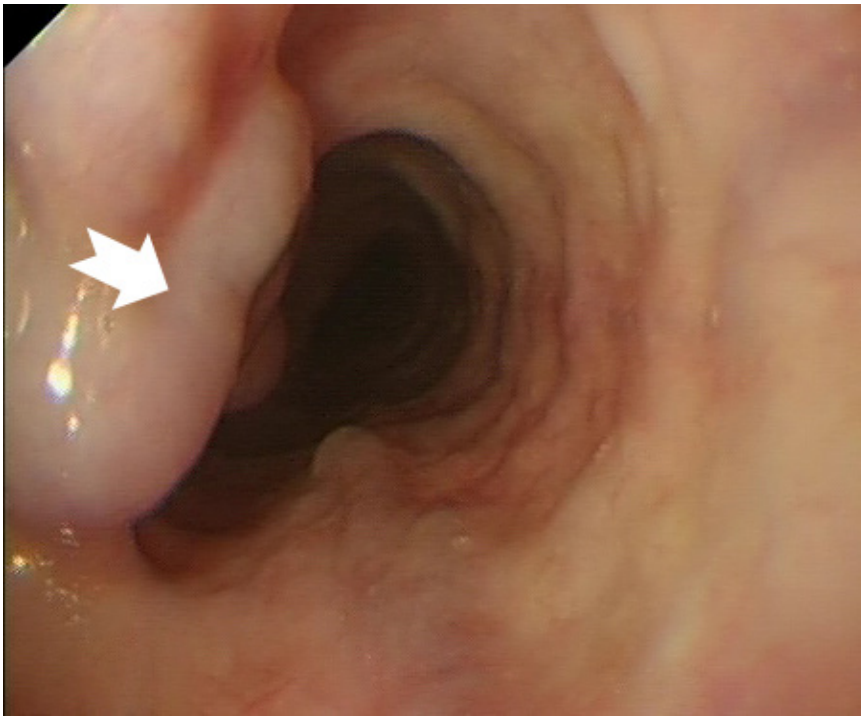

Figure 1 Endoscopic view of upper third of oesophagus.

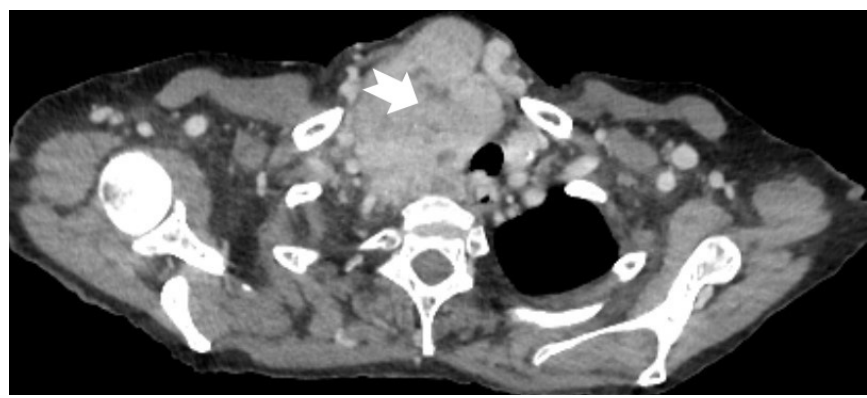

Figure 2 Axial CT image at the level of T3.

including superior vena cava obstruction and mediastinal masses. ${ }^{2-4}$ Thyroid goitre as a cause has been reported but is uncommon. ${ }^{1}$

A variety of attempted treatment options for downhill variceal haemorrhage have been reviewed, ${ }^{1}$ including band-ligation and sclerotherapy. However, endoscopic treatment of haemorrhage can be difficult due to the anatomical location and a theoretically higher risk of post procedural bleeding or perforation. ${ }^{5}$

Evidenced-based guidelines are lacking, but non-selective beta blockers or band-ligation are not recommended as prophylaxis for preventing haemorrhage. Treatment of the underlying aetiology is the preferred choice. The low risk of haemorrhage from downhill varices, supports a conservative approach where there are no stigmata of bleeding at endoscopy. ${ }^{1}$

Endoscopists should be aware that identifying proximal varices at endoscopy should trigger follow-up investigations to find an underlying cause. A multidisciplinary review following identification of the aetiology could help to determine the best management strategy for these complex cases.

Zillah Cargill ๑ , ${ }^{1}$ Tamsin Cargill, ${ }^{2}$ Brian Lei, ${ }^{3}$ Noor Bekkali, ${ }^{2}$ James East, ${ }^{2}$ Jonathan Marshall ${ }^{3}$

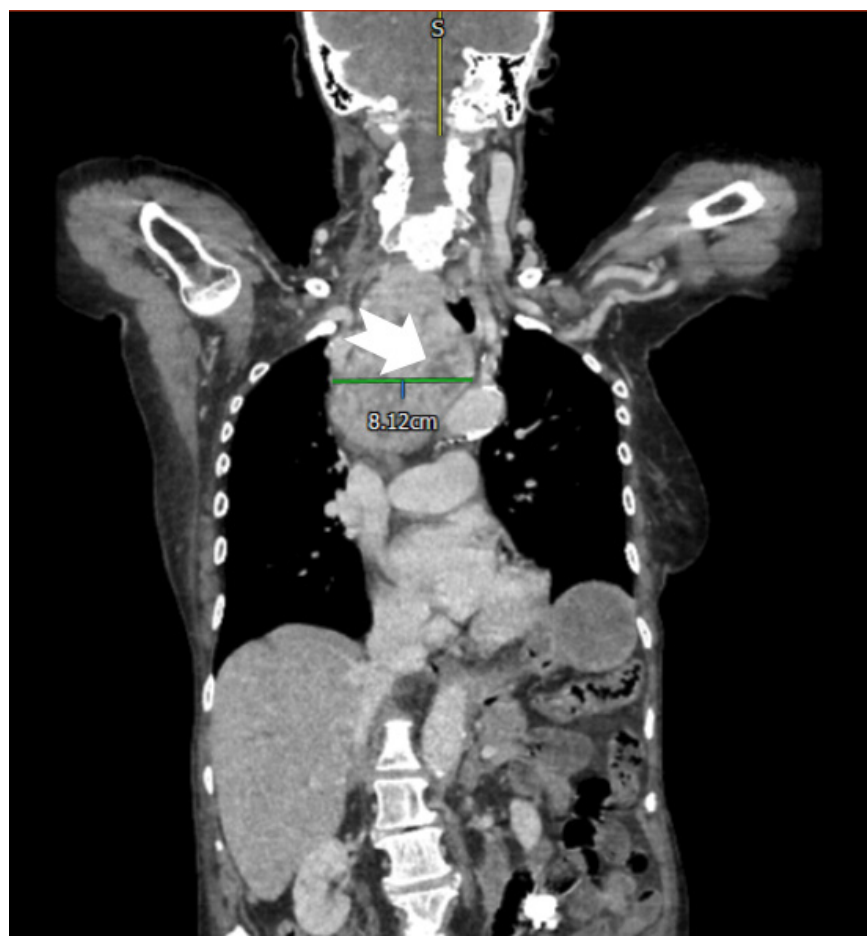

Figure 3 Coronal CT image of the chest and upper abdominal viscera showing a large left-sided irregular goitre (arrow) with normal appearance of the liver and spleen. 
${ }^{1}$ Institute of Liver Disease, King's College Hospital NHS Foundation Trust, London, UK

${ }^{2}$ Translational Gastroenterology Unit, University of Oxford, Oxford, UK

${ }^{3}$ Horton General Hospital, Oxford University Hospitals NHS Trust, Banbury, UK

Correspondence to Dr Zillah Cargill, Institute of Liver Disease, King's College Hospital NHS Foundation Trust, London SE5 9RS, UK; zillah.cargill@nhs.net

Contributors JM, NB and JE conceptualised the case report. TC and BL prepared the clinical details of the case including the images. ZC prepared the manuscript. All authors reviewed the manuscript prior to submission.

Funding TC was funded as an academic clinical fellow by NIHR and by WT training fellowship for clinicians (grant number 211042/Z/18/Z). JE was funded by the National Institute for Health Research (NIHR) Oxford Biomedical Research Centre.

Disclaimer The views expressed at those of the author(s) and not necessarily those of the National Health Service, the NIHR or the Department of Health.

Competing interests None declared.

Patient and public involvement Patients and/or the public were not involved in the design, or conduct, or reporting, or dissemination plans of this research.

Patient consent for publication Obtained.

Provenance and peer review Not commissioned; externally peer reviewed.

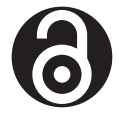

\section{OPEN ACCESS}

Open access This is an open access article distributed in accordance with the Creative Commons Attribution 4.0 Unported (CC BY 4.0) license, which permits others to copy, redistribute, remix, transform and build upon this work for any purpose, provided the original work is properly cited, a link to the licence is given, and indication of whether changes were made. See: https://creativecommons.org/ licenses/by/4.0/.

(C) Author(s) (or their employer(s)) 2020. Re-use permitted under CC BY. Published by BMJ.

\section{D) Check for updates}

To cite Cargill Z, Cargill T, Lei B, et al. Gut Epub ahead of print: [please include Day Month Year]. doi:10.1136/gutjnl-2020-322298

Received 21 June 2020

Revised 30 July 2020

Accepted 31 July 2020

Gut 2020;0:1-2. doi:10.1136/gutjnl-2020-322298

\section{ORCID iD}

Zillah Cargill http://orcid.org/0000-0002-3534-6349

\section{REFERENCES}

1 Loudin M, Anderson S, Schlansky B. Bleeding 'downhill' esophageal varices associated with benign superior vena cava obstruction: case report and literature review. BMC Gastroenterol 2016;16:134

2 Rhoades DP, Forde KA, Tabibian JH. Proximal Esophageal Varices: A Rare Yet Treatable Cause of Hemorrhage. Clin Gastroenterol Hepatol 2016;14:e105-6.

3 Nayudu SK, Dev A, Kanneganti K. "Downhill" Esophageal Varices due to Dialysis Catheter-Induced Superior Vena Caval Occlusion: A Rare Cause of Upper Gastrointestinal Bleeding. Case Rep Gastrointest Med 2013;2013:830796.

4 Siegel Y, Schallert E, Kuker R. Downhill esophageal varices: a prevalent complication of superior vena cava obstruction from benign and malignant causes. J Comput Assist Tomogr 2015;39:149-52.

5 Chakinala RC, Kumar A, Barsa JE, et al. Downhill esophageal varices: a therapeutic dilemma. Ann Transl Med 2018;6:463. 